\title{
Assistência oferecida a estudantes que relatam serem vítimas de bullying
}

Jorge Luiz da Silva. Universidade de São Paulo

Wanderlei Abadio de Oliveira. Universidade de São Paulo

Julliane Messias Cordeiro Sampaio. Centro Universitário do Distrito Federal

Fellipe Soares Salgado. Universidade de São Paulo

Beatriz Oliveira Pereira. Universidade do Minho

Marta Angélica lossi Silva.Universidade de São Paulo

\section{Resumo}

Estudo transversal que objetivou verificar se estudantes vítimas de bullying contam que estão sendo agredidos e se o tipo de agressão sofrida se relaciona à assistência que recebem. Participaram 232 estudantes do sexto ao nono ano do Ensino Fundamental que responderam um questionário autoaplicável. Os resultados indicaram um percentual de vítimas de 22,2\%. Prevaleceu para os meninos não contar a ninguém sobre as agressões sofridas e para as meninas contar aos professores. Agressão verbal se associou com não contar a ninguém, o mesmo ocorrendo em relação a se sofrer agressão psicológica e contar aos pais. Não fazer nada foi a reação predominante frente aos relatos feitos pelos meninos. Já as meninas foram auxiliadas na maioria das vezes que contaram a alguém. Houve associação entre agressão verbal e a intervenção de se conversar/orientar a vítima. Denota-se a necessidade de atenção aos relatos de bullying, com vistas ao oferecimento de intervenções resolutivas.

Palavras-chave: bullying; violência nas escolas; intervenção social; professor; pais.

\begin{abstract}
Help provided to students reporting to be victims of bullying. The objective of this cross-sectional study was to verify whether victims of bullying report when they are attacked and if the type of aggression is related to the help they receive. A total of 232 students from the 6th to the 9th grade answered a self-applied questionnaire. The results indicate a percentage of victims of the $22.2 \%$. Most of the boys did not tell anyone about aggressions, while most girls told their teachers. Verbal aggression was associated with not telling anyone, while psychological aggression was associated with telling parents. Not doing anything was the response most frequently observed among the boys, while the girls received help in most instances when they reported the problem to someone. Verbal aggression was associated with talking to/advising the victim. There is a need to establish effective interventions to cope with reports of bullying.
\end{abstract}

Keywords: bullying; school violence; social intervention; teacher; parents.

\section{Resumen}

Asistencia ofrecida a estudiantes que informaron haber sido víctimas de acoso. Un Estudio transversal tuvo como objetivo verificar si estudiantes víctimas de acoso cuentan que están siendo agredidos y si el tipo de agresión sufrida se relaciona con la asistencia que reciben. Participaron 232 estudiantes desde $6^{\circ}$ (sexto) a $9^{\circ}$ (noveno) año de Ensenãnza Primaria los cuales respondieron un cuestionario autoaplicable. Los resultados indicaron un porcentaje de víctimas de 22,2\%. Para los niños, prevaleció el no contar para nadie sobre las agresiones sufridas, y para las niñas, contar para los profesores. La agresión verbal se asoció con el no contar a nadie, aconteciendo lo mismo en relación a si se sufre una agresión psicológica y contar a sus padres. No hacer nada fue la reacción predominante frente a los relatos dados por los niños. En cambio, las niñas fueron auxiliadas la mayoría de las veces que contaron a alguien. Hubo asociación entre la agresión verbal y la intervención de conversar/orientar con la víctima. Se indica la necesidad de ofrecer intervenciones resolutivas frente a los relatos de acoso.

Palabras-clave: acoso; violencia en las escuelas; intervención social; profesor; padres. 
O bullying compreende a manifestação intencional de atitudes violentas e repetidas que são praticadas por uma ou mais pessoas em relação a seus pares. Malgrado a multiplicidade de definições presentes na literatura, observa-se uma convergência entre algumas características consideradas como fundamentais à sua conceituação: intencionalidade, repetitividade das agressões e desequilíbrio de poder (físico, psicológico ou social) entre agressor e vítima (Olweus, 2013). As agressões praticadas podem ser físicas (socos, empurrões, pontapés, entre outras), verbais (apelidos, xingamentos e insultos, por exemplo) ou psicológicas (ameaça, chantagem, isolamento social, etc.) (Sampaio et al, 2015).

A literatura especializada tem demonstrado o bullying exercendo efeitos negativos sobre o desenvolvimento e o bem estar psicossocial de crianças e adolescentes. Resumidamente, os estudantes vitimizados podem apresentar índices mais elevados de sintomatologia depressiva (Williford, Boulton, \& Jenson, 2014), ansiedade (Bauman \& Del Rio, 2006), insegurança (Sampson, 2009), solidão (Malta et al., 2014), déficits de habilidades sociais (J. L. Silva et al., 2016), dificuldade de aprendizagem escolar (Zequinão et al., 2017) e ideação suicida (Kim, Leventhal, Koh, \& Boyce, 2009). Essas consequências negativas associadas às altas taxas de prevalência do bullying, aproximadamente $40 \%$ nos países norte americanos e europeus (Due et al., 2009) e $28 \%$ no Brasil (Malta et al., 2014), colaboram para que ele seja reconhecido como problema de saúde pública (Perron, 2013).

Existem evidências de que a prática de bullying, referente às agressões de natureza física, tende a diminuir à medida que os estudantes se tornem mais velhos e progridam pelos anos escolares, de tal modo que se localiza, na maioria das vezes, maior prevalência de agressões físicas nos primeiros anos de escolarização (J. L. Silva et al., 2016). Uma possível explicação é que os alunos mais velhos são mais hábeis para se autodefenderem, devido ao maior desenvolvimento físico que apresentam. Outra explicação é a de que as formas de manifestação do bullying se alteram a partir do início da adolescência, tornando-se mais indiretas e ocultas, o que faz com que a quantidade de vítimas não diminuía realmente, porém ficam mais difíceis de serem identificadas (J. L. Silva et al., 2016).

$\mathrm{Na}$ adolescência, o envolvimento em agressões verbais e psicológicas torna-se prevalente para meninos e meninas, embora os meninos igualmente participem em maior quantidade de agressões físicas em relação às meninas (Archer, 2004). Como a maioria das agressões praticadas no bullying possui natureza velada e tendem a ocorrer em locais da escola ou em atividades que possuem menor supervisão de adultos, o relato de sua ocorrência, especialmente às autoridades escolares e aos pais é fundamental para o seu enfrentamento (Byers, Caltabiano, \& Caltabiano, 2011; Waasdorp, Bradshaw, \& Duong, 2011).

Entretanto, observa-se que o relato de agressões para a equipe escolar, com destaque para os professores, é raro, além de diminuir à medida que os estudantes ficam mais velhos. Um estudo recente indicou que as vítimas de bullying preferem contar aos amigos e aos pais (Novick \& Isaacs, 2010). Em relação a se contar aos pais, a constatação do estudo mencionado difere de um outro, mais antigo, realizando no início da década de 1990, no qual aproximadamente metade dos estudantes agredidos era relutante em relatar sua situação a pais e professores (Whitney \& Smith, 1993). Provavelmente, a maior confiança em relatar as agressões aos pais no período mais recente ocorra em função de uma maior divulgação do bullying e, consequentemente, maior informação ou conscientização dos pais acerca dos efeitos negativos desse tipo de violência no desenvolvimento psicossocial dos estudantes.

Por outro lado, Oliver e Candappa (2007), identificaram que os estudantes vitimizados avaliam cuidadosamente os riscos e benefícios de se denunciar as agressões sofridas para amigos, pais e professores. Concluíram a partir do estudo que desenvolveram que os alunos preferem contar para os amigos, por entenderem haver menos riscos de serem expostos perante os agressores e assim as agressões piorarem.Tal resistência em se denunciar as agressões sofridas não é sem fundamento, pois investigações recentes apresentam que os professores não intervêm em todos os episódios de bullying que identificam ou que lhes são relatados pelos estudantes (P. F. Silva, Freller, Alves, \& Saito, 2017; J. L. Silva, Oliveira, Bazon, \& Cecílio, 2014). Dado convergente com outro estudo, mais antigo, que destacou que $85 \%$ dos professores relatavam intervir nos incidentes de bullying, ao passo que apenas 35\% dos estudantes expressavam intervenção do professor (Pepler, Craig, Ziegler, \& Charach, 1994).

Uma possível explicação para a falta de resolutividade ou eficácia da intervenção dos professores pode se relacionar à natureza discreta da maioria das agressões, bem como a ausência de conhecimentos sobre 
as suas consequências negativas, que colabora para a interpretação de que se trata de brincadeiras típicas da infância ou adolescência (Craig, Bell, \& Leschied, 2011; J. L. Silva, Oliveira, Bazon, \& Cecílio, 2013). Os professores podem também não saberem como lidar com as situações que presenciam ou que tomam conhecimento, sentindo-se inseguros em sua capacidade de intervenção no problema (Bauman \& Del Rio, 2006; P. F. Silva et al., 2017). De todo modo, a postura que assumem diante do bullying influencia o comportamento dos alunos. Não fazer nada pode transmitir a mensagem de que a violência é tolerada ou permitida. O professor igualmente pode desempenhar um papel fundamental para o rompimento da cultura de silêncio em relação à denúncia de agressões ocorridas no ambiente escolar. Uma meta-análise desenvolvida com estudos de intervenção identificou que um componente importante para o êxito na redução do bullying constitui o grau de comprometimento do professor para acabar com a violência (Ttofi \& Farrington, 2009).

Os estudantes também têm manifestado relutância em relatar a seus pais as agressões que sofrem, seja porque se sentem envergonhados, por não quererem preocupá-los, ou pelo receio quanto à resposta que os pais podem manifestar (Oliver \& Candappa, 2007). Os pais podem responder de maneiras diferentes, o que inclui: conversar com o filho, visando orientá-lo, considerada uma postura adequada diante do relato agressões de menor gravidade; entrar em contato com a escola, igualmente considerada adequada diante do relato de agressões mais graves, quando o estudante não possui condições de por si mesmo dar fim às agressões sofridas; procurar diretamente o agressor, sendo essa uma postura inadequada; entre outras (Waasdorp et al., 2011).

Em função disso, a formação dos pais em relação a como se lidar com o bullying despontou como um dos elementos mais importantes para a diminuição deste tipo de violência na metanálise desenvolvida por Ttofi e Farrington (2009). Essa formação pode ser oferecida aos pais na própria escola, tanto por especialistas em violência ou por profissionais da educação, quando esses possuam conhecimentos e experiência no enfrentamento e prevenção da violência escolar. Um maior domínio pelos pais sobre as características do bullying, formas de manifestação, consequências negativas por ele geradas e formas da família lidar com a sua ocorrência é de suma importância para que os pais possam saber responder adequadamente aos relatos de vitimização dos filhos.
No tocante aos amigos, possuí-los representa proteção ao bullying, por constituírem uma fonte de apoio social. Os amigos se encontram em posição privilegiada para testemunhar as agressões, por compartilharem com as vítimas ambientes nos quais muitas vezes os professores ou outros adultos não se encontram presentes, podendo assim defender seus pares quando necessário. Além disso, os amigos não precisam ser convencidos de que a vítima está dizendo a verdade (Oliver \& Candappa, 2007). Contudo, na maioria das vezes os amigos não agem para defender os colegas agredidos, por não possuírem condições para enfrentarem os agressores ou por temerem também serem agredidos (Olweus, 2013).

Diante do exposto, tão importante quanto o relato do bullying é a atitude tomada pela pessoa para quem se contou (Novick \& Isaacs, 2010), no sentido de defender a vítima ou auxiliá-la a interromper as agressões. Assim, os objetivos do presente estudo foram verificar para quem as vítimas de bullying contam que estão sendo agredidas e se o tipo de agressão sofrida se relaciona ao tipo geral de assistência que recebem diante dos relatos.

\section{Método}

\section{Participantes}

Este estudo transversal foi realizado com 232 estudantes do sexto ao nono ano do Ensino Fundamental de uma escola localizada em uma cidade do interior do estado de São Paulo, dentre os quais 52 foram classificados como vítimas de bullying e compuseram a amostra que será analisada neste estudo. Esses estudantes apresentaram idade no intervalo compreendido entre 10 e 17 anos, média de 13 anos, com maior concentração na faixa etária entre 13 e 14 anos $(48,1 \%)$. Pouco mais da metade pertencia ao sexo feminino (51,9\%). Em relação ao ano escolar, a maior parte frequentava o sexto ano (26,9\%). Pouco mais de terço $(28,8 \%)$ das vítimas havia repetido de ano pelo menos uma vez. A cor da pele apresentou a seguinte distribuição: parda (44,2\%), branca $(30,7 \%)$, preta $(19,2 \%)$, amarela $(3,8 \%)$ e indígena $(1,9 \%)$.

\section{Instrumento}

Os pesquisadores elaboraram um questionário estruturado em questões fechadas e abertas ( $n=19)$, subdividido em três partes. A primeira parte visava o levantamento de informações referentes à identificação dos participantes: idade, sexo, ano escolar, reprovação 
e cor da pele. A segunda parte destinava-se à caracterização da vitimização, em termos do tipo de agressão sofrida, quantidade de vezes em que ocorreu, busca de ajuda de colegas ou adultos, reação da pessoa para quem se contou, entre outros aspectos. Na terceira parte essas questões eram replicadas com adaptações, de modo a possibilitarem a caracterização das agressões. São exemplos de questões do questionário: Você já foi agredido, ameaçado, humilhado ou excluído por colegas na escola? Nos últimos 30 dias, quantas vezes você foi agredido, ameaçado, humilhado ou excluído por colegas na escola? Você contou para alguém quando isso aconteceu? Quando você contou o que aconteceu? O questionário foi analisado por três juízes especialistas em violência escolar que avaliaram o seu conteúdo, bem como procedeu-se uma aplicação preliminar em um grupo de estudantes $(n=23)$ do Ensino Fundamental, com o objetivo de se testar a adequação das questões do questionário à compreensão dos adolescentes. Esse pré-teste foi realizado em uma escola pública, com características semelhantes à escola do estudo definitivo (Sampaio et al., 2015).

\section{Procedimento de Coleta de Dados}

A seleção da escola ocorreu por acessibilidade, devido a um vínculo prévio existente com o grupo de pesquisa ao qual pertencem os pesquisadores, na qual são realizadas outras atividades de pesquisa e extensão universitária. Os dados foram coletados em todas as turmas do sexto ao nono ano do Ensino Fundamental durante o horário de aula. Os critérios para inclusão e participação dos alunos no estudo foram: estar regularmente matriculado na escola; ser frequente às aulas; estar presente no dia de aplicação do questionário; ter concordado em colaborar com a pesquisa mediante assinatura ao Termo de Assentimento e ter apresentado o Termo de Consentimento Livre e Esclarecido (TCLE) assinado por um responsável. Anteriormente à aplicação do questionário, os pesquisadores explicaram aos estudantes como preenchê-lo e, no decorrer da aplicação, ficaram de prontidão para o esclarecimento de dúvidas. O tempo médio para conclusão do preenchimento do questionário era de aproximadamente 30 minutos.

\section{Análise dos Dados}

Com o auxílio do software SAS (versão 9.2), realizou-se uma análise descritiva das informações em frequência e percentuais, com o objetivo de possibilitar uma visão global da variação dos valores apresentados. Os resultados foram organizados em tabelas com as medidas descritivas. Nesse momento foram identificados como vítimas os estudantes que referiram terem sofrido agressões por três ou mais vezes nos últimos 30 dias. Posteriormente, aplicou-se o Teste Exato de Fischer para comparar o tipo de agressão sofrida pelas vítimas e para quem contaram, com vistas à identificação de associação entre essas variáveis. O mesmo procedimento foi adotado em relação ao tipo de agressão e ao tipo de ajuda recebida. O nível de significância utilizado para todas as análises foi de $5 \%(p<0,05)$.

\section{Aspectos Éticos}

Em todas as etapas da investigação foram seguidas as recomendações e orientações da resolução 466/2012 do Conselho Nacional de Saúde. O projeto de pesquisa foi submetido e aprovado pelo Comitê de Ética em Pesquisa da Escola da Enfermagem de Ribeirão Preto da Universidade de São Paulo (Protocolo 1422/2011, Parecer 471/2011). Também se obteve autorização da direção da escola. Antes da coleta dos dados, os alunos receberam informações detalhadas sobre a pesquisa $\mathrm{e}$, àqueles que demonstraram interesse em colaborar com o estudo, apresentou-se o Termo de Assentimento e o Termo de Consentimento Livre e Esclarecido (TCLE) que foram assinados pelos alunos e seus responsáveis, respectivamente.

\section{Resultados}

No tocante ao envolvimento em situações de bullying, obteve-se que $22,2 \%(n=52)$ dos participantes se enquadravam no perfil de vítimas. Na Tabela 1 são apresentados os tipos e subtipos de agressões praticados contra as vítimas.

Identificou-se que dentre as agressões mais praticadas em relação às vítimas destacaram-se aquelas de tipo verbal, tanto para as meninas ( $n=53,71,6 \%$ ) quanto para os meninos ( $n=37,68,5 \%)$. Em termos de proporção entre os sexos, a frequência dos subtipos de agressão verbal sofridos seguiu a mesma ordem: caçoar, apelidar e xingar. Insultar obteve a menor proporção entre os quatro subtipos investigados.

O segundo tipo de agressão mais sofrido pelos estudantes vitimizados diferiu entre os sexos, destacando-se agressão física para os meninos ( $n=11,20,4 \%$ ) e agressão psicológica para as meninas ( $n=14,18,9 \%)$. A agressão física prevalente se relacionou a danos de natureza material referentes a se estragar pertences. Não obstante, ataques direcionados à integridade física das vítimas também ocorreram em proporção menor. 
Tabela 1. Frequência dos Tipos e Subtipos de Agressões Sofridos, segundo o Sexo $(n=52)$

\begin{tabular}{lcccc}
\hline \multicolumn{1}{c}{ Tipo de agressão } & $\begin{array}{c}\text { Meninos }(\mathbf{n}=\mathbf{2 5}) \\
\text { Frequência }\end{array}$ Porcentagem & $\begin{array}{c}\text { Meninas }(\mathbf{n}=\mathbf{2 7}) \\
\text { Frequência }\end{array}$ \\
\hline $\begin{array}{l}\text { Física } \\
\quad \text { Estragar pertencestagem }\end{array}$ & 6 & 11,1 & 4 & 5,4 \\
$\begin{array}{l}\text { Bater, chutar ou } \\
\text { esmurrar }\end{array}$ & 5 & 9,3 & 3 & 4,1 \\
Verbal & & & & \\
$\quad$ Caçoar & 14 & 25,9 & 23 & 31,1 \\
Apelidar & 14 & 25,9 & 20 & 27,0 \\
Xingar & 6 & 11,1 & 9 & 12,1 \\
Insultar & 3 & 5,6 & 1 & 1,4 \\
Psicológica & & & & \\
Fofocar & 3 & 5,6 & 11 & 14,8 \\
Ameaçar & 2 & 3,7 & 1 & 1,4 \\
Isolar & 1 & 1,8 & 2 & 2,7 \\
\hline Total & 54 & 100 & 74 & 100 \\
\hline
\end{tabular}

No tocante às agressões psicológicas, os subtipos mais frequentes foram fofocar, ameaçar e isolar o colega, sendo que a fofoca apresentou ocorrência mais elevada, especialmente para as meninas.

Tabela 2. Frequência de Contar a Alguém sobre a Agressão Sofrida, segundo o Sexo $(n=52)$

Identificou-se uma diferença entre os sexos ati-

\begin{tabular}{lcccc}
\hline & \multicolumn{2}{c}{ Meninos $(\mathbf{n}=\mathbf{2 5})$} & \multicolumn{2}{c}{ Meninas $(\mathbf{n}=\mathbf{2 7})$} \\
& Frequência & Porcentagem & Frequência & Porcentagem \\
\hline Ninguém & 11 & 39,3 & 4 & 11,8 \\
Professor & 8 & 28,5 & 12 & 35,2 \\
Amigos & 6 & 21,4 & 5 & 14,7 \\
Pais & 2 & 7,2 & 9 & 26,5 \\
Familiares & 1 & 3,6 & 4 & 11,8 \\
\hline Total & 28 & 100 & 34 & 100 \\
\hline
\end{tabular}

nente a se contar a alguém sobre as agressões sofridas, prevalecendo para os meninos não contar a ninguém ( $n=11,39,3 \%$ ), ao passo que para as meninas preponderou contar ao professor ( $n=12,35,2 \%)$. Contar aos pais também se destacou para as meninas enquanto segunda opção com maior frequência. Já os meninos, quando relataram a alguém sobre as agressões sofridas, o fizeram aos professores $(n=8,28,5 \%)$. Tanto as meninas quanto os meninos procuram ajuda dos professores quando estão sendo agredidos por colegas na escola, bem como que a meninas procuram mais apoio com adultos ( $n=25,73,5 \%$ ), o que representa quase o dobro do resultado apresentado pelos meninos ( $n=9,39,3 \%$ ).

Quando comparados os tipos de agressão sofridos e a pessoa para quem se relatou o ocorrido, sofrer agressão verbal se associou estatisticamente com não contar a ninguém $(p<0,001)$. Também se localizou diferença significativa entre sofrer agressão psicológica e contar aos pais $(p<0,05)$. As demais associações não apresentaram significância estatística.

Tabela 3. Assistência Oferecida à Vítima que Contou sobre a Agressão Sofrida, segundo o Sexo $(n=37)$

\begin{tabular}{lcccc}
\hline & \multicolumn{2}{c}{ Meninos $(\mathbf{n}=\mathbf{1 4})$} & \multicolumn{2}{c}{ Meninas $(\mathbf{n}=\mathbf{2 3})$} \\
& Frequência & Porcentagem & Frequência & Porcentagem \\
\hline $\begin{array}{l}\text { Não fez nada } \\
\begin{array}{l}\text { Chamou a } \\
\text { atenção }\end{array}\end{array}$ & 5 & 35,7 & 5 & 21,7 \\
$\begin{array}{l}\text { Ajudou de outra } \\
\text { forma }\end{array}$ & 3 & 21,4 & 6 & 26,1 \\
$\begin{array}{l}\text { Não acreditou } \\
\text { Conversou }\end{array}$ & 2 & 14,3 & - & 26,1 \\
\hline Total & 1 & 7,2 & 6 & - \\
\hline
\end{tabular}

Os resultados referentes aos estudantes vitimizados que contaram a alguém sobre agressões contra eles praticadas (Tabela 3 ) revelam que não se fazer nada ( $n$ $=5,35,7 \%$ ) prevaleceu diante do relato dos meninos. Fazer nada e não acreditar representou para os meninos $50 \%(n=7)$ das reações das pessoas para quem contaram. Em contraposição, não foram registradas ocorrências de não se acreditou quando o relator era do sexo feminino. Fazer nada mediante o relato da agressão também apresentou frequência menor para as meninas ( $n=5,21,7 \%$ ). Somente uma associação entre tipo de agressão e o tipo de ajuda oferecida demonstrou diferença estatisticamente significativa: sofrer agressão psicológica e conversar $(p<0,001)$, no sentido de orientar a vítima quanto ao que poderia ser feito para melhorar a sua situação.

\section{Discussão}

Os resultados deste estudo demonstraram que na realidade investigada a frequência de vitimização por bullying foi três vezes superior à média identificada por um estudo brasileiro realizado com uma amostra nacionalmente representativa (Malta et al., 2014). Não obstante, a literatura apresenta resultados distintos no tocante às taxas de prevalência de bullying, com resultados que variam de $8 \%$ a $38 \%$ para vitimização (Sampson, 2009). Uma justificativa para as distinções nos resultados de diferentes estudos reside na definição de bullying. Embora haja convergência nas diferentes terminologias utilizadas, no sentido de compartilharem características em comum, a ausência de 
definição única interfere no modo como o fenômeno é compreendido. Por exemplo, os termos ijime no Japão, prepotanza na Itália e zorbalik na Turquia não correspondem exatamente à definição de bullying na língua inglesa (Duy, 2013).

Existem também diferenças no modo como o fenômeno é mensurado em relação à sua ocorrência (Rech, Halpernb, Tedesco, \& Santos, 2013). Algumas investigações apresentam uma definição de bullying e em seguida perguntam se o participante da pesquisa foi agressor ou vítima. Outros estudos elencam uma série de comportamentos agressivos e os participantes sinalizam se praticaram ou foram alvos desses comportamentos (Sampaio et al., 2015; J. L. Silva et al., 2016). Os instrumentos utilizados igualmente apresentam variações, muitos são construídos e não validados e outros constituem instrumentos estrangeiros que são traduzidos e aplicados, porém não adaptados ou validados para aplicação na realidade nacional, o que compromete a qualidade dos dados obtidos com esses instrumentos (Alckmin-Carvalho, Izbicki, Fernandes, \& Melo, 2014). O bullying igualmente se encontra influenciado por diferenças sociais e culturais, variando de acordo com a realidade sociocultural em estudo (Antunes \& Zuin, 2008; Zequinão et al., 2017). Contudo, tendo em vista a gravidade das consequências negativas desencadeadas pelo bullying, é fundamental o seu enfrentamento e prevenção no contexto escolar investigado, independentemente da prevalência que apresente.

No tocante às agressões mais praticadas contra as vítimas, preponderaram aquelas de tipo verbal para ambos os sexos. Resultado que pode ser interpretado na linha das proposições feitas por J. L. Silva et al. (2013) que, baseados no estudo que realizaram com professores sobre bullying na sala de aula, concluíram que possivelmente as agressões verbais ocorriam em maior quantidade para ambos os sexos em função de serem interpretadas pelos professores como possuindo menor gravidade, sendo menos passíveis de intervenção. Esse resultado também apresenta relação com a literatura internacional que aponta uma tendência referente à diminuição da quantidade de agressões físicas à medida que os estudantes se tornam mais velhos, em função de começarem a praticar agressões mais sutis, por serem de difícil identificação pelas autoridades escolares (Atlas \& Pepler, 1998; Nesdale \& Pickering, 2006).

Em termos de proporção, os meninos deste estudo sofreram mais agressões físicas em relação às meninas que, em seu turno, relataram mais agressões psicológicas. Esse dado se coaduna com a literatura que indica as agressões físicas sendo mais praticadas e sofridas pelos meninos (Archer, 2004; Sampaio et al., 2015). Tais agressões são mais fáceis de serem identificadas e de ter o seu dano avaliado, por exemplo, um braço quebrado é mais grave do que um beliscão. Apesar disso, é importante destacar que, embora sejam mais visíveis, corre-se o risco das agressões físicas serem interpretadas por um viés normativo, naturalizadas nas interações sociais dos meninos devido à sua alta ocorrência, ficando assim menos passíveis de sofrerem intervenção pela equipe escolar.

Portanto, a relação entre agressões físicas e sexo masculino pode destituir tais agressões de sua gravidade e aspecto prejudicial para os meninos participantes deste estudo. Tal percepção pode refletir no modo como são tratadas pelas autoridades escolares as situações que presenciam ou que lhes são denunciadas. A mesma situação pode ser experimentada pelas meninas por sofrerem mais agressões psicológicas, interpretadas por alguns adultos como inerentes às relações sociais entre as mulheres, em razão delas se envolverem mais em situações de intrigas e provocações (Archer, 2004).

A esse respeito, compete destacar que, apesar de existirem evidências indicando que as agressões psicológicas geralmente são interpretadas pelos professores como possuindo natureza menos grave, as vítimas desta violência a classificam como sendo o pior de todas, especialmente a exclusão social (Byers et al., 2011). Ademais, as agressões psicológicas são mais fortemente relacionadas ao estresse emocional do que as agressões físicas, apresentando também maior ligação com a depressão e ideação suicida (Bauman \& Del Rio, 2006). Um agravante, nestes casos, é que as agressões físicas diminuem com a idade, porém as psicológicas tendem a aumentarem, por serem mais implícitas e de difícil identificação. Circunstância que se apresenta mais desfavorável para as meninas participantes deste estudo.

Os meninos expressaram relutância em contar para alguém sobre as agressões sofridas. Tal resistência pode ser explicada em parte devido ao receio de se exporem e sofrerem represálias por parte dos agressores ou mesmo por não confiarem na capacidade das outras pessoas para ajudá-los. Existe ainda a possibilidade dos seus relatos serem desacreditados ou minimizados pelos adultos que, por não intervirem, aumentam a sensação de desamparo nas vítimas (Craig et al., 2011). Outro fator suscetível de exercer impacto sobre 
o relato de agressões diz respeito a determinadas posturas valorizadas pelo grupo de pares, tais como, por exemplo, não envolver a participação de adultos nas relações entre eles estabelecidas, que se traduz em não "dedurar" a violência praticada pelos colegas (Oliver \& Candappa, 2007).

Como o bullying muitas vezes constitui uma atividade exercida em grupo, esses apontamentos ajudam a esclarecer a diferença encontrada entre os sexos, uma vez que os meninos podem ser mais suscetíveis a atenderem as exigências culturais que incidem sobre eles, especialmente em relação à transmissão de imagem de masculinidade, de modo a evitarem com maior intensidade a rejeição pelos pares (Seaton, 2007; J. L. Silva et al., 2013). Noutra perspectiva, a busca por maior autonomia pessoal na adolescência pode reforçar a vontade de se querer lidar com as agressões sofridas sem o auxílio de outras pessoas, o que também pode se encontrar relacionado à postura apresentada pelos meninos.

Em contraposição, a maioria das meninas preferiu contar a alguém que estavam sendo agredidas por colegas na escola, especialmente para professores e pais. Assim, os dados indicam uma característica do processo de socialização feminina apresentado pela literatura, que se trata do comportamento de buscar e manter relações com maior nível de intimidade (Luke, 2008). Para as meninas o estabelecimento de relações fortes de amizade, não somente em relação a colegas, se encontra relacionado à sua formação identitária e essa forma de comportamento social pode se estender mais facilmente às relações com os professores. Os resultados apontaram que as meninas mantêm relações de confiança com adultos em maior proporção aos meninos. Em contrapartida, o fato de contarem menos para amigos pode se relacionar às indicações de que geralmente o bullying praticado contra as meninas é de natureza social, mediante principalmente ataques à reputação. Agressão que, muitas vezes, resulta na exclusão da vítima do grupo de pares (Archer, 2004). 0 isolamento social pode impedir a busca de ajuda com os amigos ou implicar na falta de confiança neles.

A maior quantidade de relatos das meninas para os adultos pode indicar ainda que o sexo dos adolescentes envolvidos nas situações de bullying afeta a forma como professores e pais percebem as agressões, no sentido de atribuírem maior gravidade quando acontecem com as meninas, de modo a intervirem com maior intensidade nesses casos (Hektner \& Swenson, 2012). A esse respeito, a pesquisa de Smith e Shu (2000) demonstrou que contar aos professores foi mais eficaz para diminuir as práticas de bullying em relação às meninas.

A constatação de que os meninos participantes deste estudo contam menos com o apoio de adultos merece destaque, uma vez que, se o bullying implica, via de regra, em desequilíbrio de poder, as vítimas por si mesmas não possuem condições adequadas para autodefesa. Portanto, o papel desempenhado pelos adultos, especialmente os professores, é fundamental para a interrupção das agressões. Nesse sentido, o estudo desenvolvido por Smith e Shu (2000) constatou que, apesar da relutância das vítimas para contar a alguém, o relato ao professor ou membro da família foi por elas percebido como tendo um impacto positivo sobre a sua situação. Não obstante, são os adultos, especialmente os professores, as pessoas mais capacitadas para propiciarem intervenções mais adequadas e que efetivamente interrompam o ciclo de agressões.

Não se trata, entretanto, de responsabilizar unicamente os professores pelo enfrentamento desta questão nas escolas, uma vez que, sendo o bullying uma problemática complexa e multideterminada, exige igualmente respostas complexas, articuladas e abrangentes, assinaladas pela multiplicidade de agentes e contextos. A ausência de uma política pública nacional de combate ao bullying é um atenuante ao seu enfrentamento na escola, de igual modo a desarticulação na atuação entre os professores/gestão escolar e a ausência muitas vezes de um plano institucional de combate à violência. Frisa-se ainda a pouca ou a ausência da participação das famílias na vida escolar dos filhos. Contudo, apesar dos aspectos mencionados, os professores se encontram em posição privilegiada para intervirem nas situações de bullying, de modo a interromperem as agressões no momento em que ocorrem em sala de aula, evitando, assim que se agravem para atos de maior gravidade. Também podem atuar de forma preventiva, conscientizando os estudantes em relação à gravidade das ações de bullying.

A diferença estatisticamente significativa localizada entre sofrer agressão verbal e não contar a ninguém igualmente encontra respaldo na literatura. Em diversas realidades socioculturais é possível identificar que as agressões físicas são consideradas como possuindo maior gravidade (Duy, 2013; J. L. Silva et al., 2014). Assim, os adolescentes participantes deste estudo podem não denunciar a prática de agressões 
verbais por considerarem que não obterão resposta favorável de professores, pais, amigos ou familiares.

Importa destacar que, embora a angústia das vítimas muitas vezes não seja visível, os problemas emocionais e sociais gerados pela violência verbal não podem ser menosprezados e medidas direcionadas ao seu enfrentamento necessitam serem empreendidas, visando à sua interrupção. A ausência de intervenção pode transmitir a mensagem de que os adultos são indiferentes ou incapazes de oferecerem proteção, o que desestimula que novas agressões sejam relatadas (J. L. Silva et al., 2014).

Por se manifestarem de modo implícito e sutil, as agressões psicológicas são mais difíceis de identificar, bem como de se provar a sua ocorrência para as autoridades escolares. Talvez esse seja o motivo pelo qual os adolescentes investigados preferiram relatar tais agressões para os pais, cuja proporção apresentou significância estatística. A relutância em expor a situação aos professores pode partir de diferentes causas: receio de os professores não acreditarem nos relatos, revelarem o episódio ocorrido ao agressor ou medo de que os professores em vez de resolver agravem o problema (Oliver \& Candappa, 2007). No entanto, muitos pais podem não saber como auxiliar os filhos a superarem o estado de vitimização e incentivarem ações ineficazes para a superação do problema da vitimização dos filhos. Por exemplo: pedir para revidar as agressões ou o próprio pai confrontar o estudante agressor.

Por outro lado, o tipo de agressão sofrida também pode interferir no modo como os pais respondem aos relatos de bullying. Waasdorp et al. (2011) identificaram que os pais eram menos propensos a entrarem em contato com as escolas quando seus filhos eram alvo de ataques de natureza psicológica. Apesar destas considerações, os resultados deste estudo sinalizam que na realidade por ele investigada o relato de agressões psicológicas aos pais pode indicar que os genitores sejam mais receptivos e propensos a intervirem para auxiliarem neste tipo de agressão, em contraposição aos resultados de Waasdorp et al. (2011).

No tocante à assistência oferecida pela pessoa para quem se contou sobre a agressão sofrida, não se fazer nada foi uma tônica para os meninos. Quando falta intervenção por parte dos professores, a quantidade e intensidade das agressões tendem a aumentarem na escola (J. L. Silva et al., 2013). A investigação de Crothers, Kolbert e Barker (2006) demonstrou que os estudantes reconhecem a influência exercida pelos professores no enfrentamento da violência entre pares, destacando que uma gestão eficaz das situações ocorridas em sala de aula seria a melhor intervenção a ser empreendida pelos professores para cessar os episódios de bullying.

Contudo, é importante destacar que a atuação do professor em sala de aula não se encontra desvinculada de aspectos institucionais da escola, das políticas públicas educacionais e das condições objetivas de seu trabalho. Destaca-se, portanto, a importância da atuação conjunta dos professores com os demais membros da comunidade escolar, especialmente aqueles diretamente ligados à gestão da escola, responsáveis por receberem encaminhamentos nas situações de maior gravidade, contatarem as famílias dos estudantes e articularem ações de prevenção e combate à violência empreendidas na escola (J. L. Silva et al., 2013).

Para os participantes do sexo masculino deste estudo, prevalece a falta de ajuda por parte de professores, pais, familiares e amigos ou a descrença na veracidade dos seus relatos. Considerando-se que a maioria das vítimas não possui condições próprias para autodefesa, a ausência de auxílio para os meninos pode representar a continuidade das agressões por um período maior de tempo, abrindo caminho para o surgimento de problemas escolares, comportamentais e de saúde (Lisboa, Braga, \& Ebert, 2009; Zaine, Reis, \& Pandovani, 2010).

É importante destacar, entretanto, que o não fazer nada não se relaciona absolutamente à indiferença pelo outro, pode ser motivado também pelo não saber como agir diante da situação, especialmente em relação aos amigos que também são crianças e adolescentes. Estudos indicam que muitas vezes os pares desejam ajudar o colega intimidado, porém não sabem como fazer ou então não se sentem suficientemente preparados para enfrentarem os agressores (J. L. Silva et al., 2016). Em função disso, existem intervenções desenvolvidas internacionalmente que priorizam a preparação/formação dos pares para não apoiarem os agressores e agirem em defesa das vítimas. Um exemplo é o Programa KiVa desenvolvido na Finlândia e em alguns outros países e que apresenta resultados positivos na prevenção e redução do bullying escolar (Ttofi \& Farrington, 2009).

A associação estatisticamente significativa entre sofrer agressão psicológica e a reação de conversar pode ter relação com o fato deste tipo de agressão ter sido mais relatado aos pais, indicando que eles preferem na maioria das vezes conversar e orientar os filhos. 
Deste modo, podem dialogar com os filhos sobre formas mais adaptativas para se lidar com a violência entre pares na escola, bem como auxiliá-los a lidarem com as emoções negativas decorrentes das agressões sofridas (Waasdorp et al., 2011). Noutra perspectiva, os pais podem não conhecer outras formas de se lidar com o problema. Importante também é que os pais procurem as escolas para construírem conjuntamente propostas de intervenção mais complexas e articuladas, uma vez que existem evidências apontando a relevância da colaboração entre famílias e escolas para evitar mais eficazmente o bullying (Duy, 2013).

\section{Considerações finais}

Sumariamente, os resultados deste estudo indicaram que meninos e meninas sofreram mais agressões verbais. Prevaleceu para os meninos não contar a ninguém sobre a sua condição de vítima, ao passo que as meninas preferiram contar para adultos. A metade dos meninos que relataram a alguém sobre as agressões que sofriam não receberam nenhum tipo de auxílio da pessoa para quem contaram ou essa pessoa não acreditou no relato. Em contraposição, para a maioria das meninas foi oferecido algum tipo de assistência. Identificou-se uma preferência das vítimas em relatarem aos pais os episódios de agressão psicológica, bem como de não contarem a ninguém as situações de agressão verbal. $A$ intervenção mais comum diante de agressões psicológicas foi conversar com vítima.

Contudo, algumas limitações devem ser consideradas na interpretação dos resultados deste estudo. A primeira delas se refere à amostra de conveniência, representada por apenas uma escola pública, o que limita a possibilidade de generalização dos resultados. Pesquisas futuras, com objetivos semelhantes, podem trabalhar com amostras maiores e mais diversificadas, incluindo escolas públicas e privadas, com vistas a promover avanços sobre os achados deste estudo, estendendo seu alcance e possibilitando a generalização dos resultados.

Outra limitação desta pesquisa diz respeito ao seu delineamento transversal, que impede a realização de inferências sobre direção das associações identificadas, não permitindo o estabelecimento de relações de causalidade. Pesquisas futuras podem adotar delineamento longitudinal, por esse possibilitar o acompanhamento de alterações ocorridas ao longo do tempo, de modo a identificar os efeitos exercidos por uma variável sobre outra, o que permite inferir relações de causa e efeito. Assim, poder-se-á esclarecer as razões para relutância dos adolescentes relatarem as agressões para outras pessoas, principalmente para os adultos, de modo a se identificar se isso ocorre em razão da falta do oferecimento de ajuda diante dos relatos dos estudantes, intervenções inadequadas, medo de represálias dos agressores ou por questões voltadas ao desenvolvimento da autonomia na adolescência.

O presente estudo foi limitado também por apresentar opções gerais de ajuda a serem sinalizadas pelos participantes. Assim, fica a necessidade de maior aprofundamento desta relação mediante estudos qualitativos, mais adequados à investigação idiossincrática de fenômenos sociais. Cumpre destacar, ainda, que os resultados referentes a se contar a alguém, bem como aqueles concernentes à intervenção, podem ser influenciados por variáveis que não foram incluídas nesta investigação. Por exemplo, a quantidade de agressões sofridas, a história global de vitimização do adolescente, o papel que desempenha na dinâmica do bullying (vítima típica, agressora ou provocadora), a qualidade da relação da vítima com pais e professores, as estratégias de resposta utilizadas para enfrentar ou se esquivar das agressões, o clima escolar, a formação de professores para lidar com o bullying, bem como questões culturais, comunitárias, entre outras. Todos esses aspectos são relevantes para a compreensão do fenômeno a partir de uma perspectiva mais ampla e podem constituir temáticas para futuras pesquisas na realidade nacional, na qual o tema ainda é pouco investigado.

Apesar das limitações apresentadas, os resultados deste estudo ajudaram a esclarecer, na realidade investigada, se as vítimas de bullying relatam as agressões sofridas, bem como o tipo de ajuda que recebem, destacando as diferenças existentes entre os sexos, o que permitiu identificar a necessidade de se oferecer maior atenção aos relatos de bullying, com vistas ao oferecimento de intervenções eficazes e resolutivas. Ademais, como a maioria das agressões de bullying ocorre no ambiente escolar, torna-se fundamental que as escolas proporcionem oportunidades para que os estudantes agredidos se sintam seguros o suficiente para contarem aos professores ou equipe escolar sobre a sua situação. $O$ estabelecimento de parcerias com as famílias desses estudantes igualmente se mostra relevante, na medida em que intervenções mais abrangentes e integradas se mostram mais eficazes no enfrentamento da violência. 


\section{Referências}

Alckmin-Carvalho, F., Izbicki, S., Fernandes, L. F. B, \& Melo, M. H. S. (2014). Estratégias e instrumentos para a identificação de bullying em estudos nacionais. Avaliação Psicológica, 13(3), 343-350. Recuperado de http://pepsic.bvsalud.org/scielo.php?script=sci_arttext\&pid=S1677-04712014000300006\&lng=pt\&tIng=pt

Antunes, D. C., \& Zuin, A. A. S. (2008). Do bullying ao preconceito: os desafios da barbárie à educação. Psicologia \& Sociedade, 20(1), 33-42. doi: 10.1590/S0102-71822008000100004

Archer, J. (2004). Sex differences in aggression in real-world settings: a meta-analytic review. Review of General Psychology, 8(2), 291-322. doi: 10.1037/1089-2680.8.4.291

Atlas, R. S., \& Pepler, D. J. (1998). Observations of bullying in the classroom. Journal of Educational Research, 92, 86-99.

Bauman, S., \& Del Rio, A. (2006). Preservice teachers' responses to bullying scenarios: Comparing physical, verbal, and relational bullying. Journal of Educational Psychology, 98(1), 219-231. doi: 10.1037/0022-0663.98.1.219

Byers, D. L., Caltabiano, N. J., \& Caltabiano, M. L. (2011). Teachers' attitudes towards overt and covert bullying, and perceived efficacy to intervene. Australian Journal of Teacher Education, 36(11), 105119. doi: 10.14221/ajte.2011v36n11.1

Craig, K., Bell, D., \& Leschied, A. (2011). Pre-service teachers' knowledge and attitudes regarding school-based bullying. Canadian Journal of Education, 34(2), 21-33. Recuperado de http://journals. sfu.ca/cje/index.php/cje-rce/article/view/410

Crothers, L. M., Kolbert, J. B., \& Barker, W. F. (2006). Middle school students' preferences for anti-bullying interventions. School Psychology International, 27(4), 475-487. doi: 10.1177/0143034306070435

Due, P., Merlo, J., Harel-Fisch, Y., Damsgaard, M. T., Holstein, B. E., Hetland, J., ... Currie, C. (2009). Socioeconomic inequality in exposure to bullying during adolescence: a comparative, cross-sectional, multilevel study in 35 countries. American Journal of Public Health, 99(5), 907-14. doi: 10.2105/AJPH.2008.139303

Duy, B. (2013). Teachers' attitudes toward different types of bullying and victimization in Turkey. Psychology in the Schools, 50(10), 987-1002. doi: $10.1002 /$ pits. 21729

Hektner, J. M., \& Swenson, C. A. (2012). Links from teacher beliefs to peer victimization and bystander intervention tests of mediating processes. The Journal of Early Adolescence, 32(4), 516-536. doi: $10.1177 / 0272431611402502$

Kim, Y., Leventhal, B., Koh, Y. J., \& Boyce, W. T. (2009). Bullying increased suicide risk: prospective study of Korean adolescents. Archives of Suicide Research, 13(1), 15-30. doi: 10.1080/13811110802572098

Lisboa, C., Braga, L. L., \& Ebert, G. (2009). O fenômeno bullying ou vitimização entre pares na atualidade: definições, formas de manifestação e possibilidades de intervenção. Contextos Clínicos, 2(1), 59-71. doi: $10.4013 /$ ctc.2009.21.07

Luke, K. (2008). Are girls really becoming more violent? A critical analysis. Affilia, 23(1), 38-50. doi: 10.1177/0886109907310461

Malta, D. C., Porto, D. L., Crespo, C. D., Silva, M. M. A., Andrade, S. S. C., Mello, F. C. M., ... Silva, M. A. I. (2014). Bullying in Brazilian school children: analysis of the National Adolescent School-based Health Survey (PeNSE 2012). Revista Brasileira de Epidemiologia, 17(1), 92-105. doi: 10.1590/1809-4503201400050008

Nesdale, D., \& Pickering, K. (2006). Teachers' reactions to children's aggression. Social Development, 15(1), 109-127. doi: 10.1111/j.1467-9507.2006.00332.x
Novick, R. M., \& Isaacs, J. (2010). Telling is compelling: the impact of student reports of bullying on teacher intervention. Educational Psychology, 30(3), 283-296. doi: 10.1080/01443410903573123

Oliver, C., \& Candappa, M. (2007). Bullying and the politics of 'telling'. Oxford Review of Education, 33(1), 71-86. doi: $10.1080 / 03054980601094594$

Olweus, D. (2013). School bullying: development and some important challenges. Annual Review of Clinical Psychology, 9, 751-780. doi: 10.1146/annurev-clinpsy-050212-185516

Pepler, D. J., Craig, W. M., Ziegler, S., \& Charach, A. (1994). An evaluation of an antibullying intervention in Toronto schools. Canadian Journal of Community Mental Health, 13(2), 95-110. doi: 10.7870/ cjcmh-1994-0014

Perron, T. (2013). Peer victimisation: strategies to decrease bullying in schools. British Journal of School Nursing, 8(1), 25-29. doi: 10.12968/bjsn.2013.8.1.25

Rech, R. R., Halpern, R., Tedesco, A., \& Santos, D. F. (2013). Prevalence and characteristics of victims and perpetrators of bullying. Jornal de Pediatria, 89(2), 164-170. doi: 10.1016/j.jped.2013.03.006

Resolução n. 466, de 12 de dezembro de 2012. (2012, 12 de dezembro). Aprova diretrizes e normas regulamentadoras de pesquisas envolvendo seres humanos. Diário Oficial da União, seção 1.

Sampaio, J. M. C., Santos, G. V., Oliveira, W. A., Silva, J. L., Medeiros, M., \& Silva, M. A. I. (2015). Prevalência de bullying e emoções de estudantes envolvidos. Texto \& Contexto - Enfermagem, 24(2), 344352. doi: 10.1590/0104-07072015003430013

Sampson, R. (2009). Bullying in Schools. Nova lorque, NY: Center for Problem-Oriented Policing.

Seaton, E. (2007). Exposing the invisible: unraveling the roots of rural boys' violence. Journal of Adolescent Research, 22(3), 211-218. doi: $10.1177 / 0743558407300345$

Silva, J. L., Oliveira, W. A., Bazon, M. R., \& Cecilio, S. (2013). Bullying na sala de aula: percepção e intervenção de professores. Arquivos Brasileiros de Psicologia, 65(1), 121-137.

Silva, J. L., Oliveira, W. A., Bazon, M. R., \& Cecilio, S. (2014). Bullying: conhecimentos, atitudes e crenças de professores. Psico, 45(2), 147-156. doi: 10.1590/S1413-73722012000200008

Silva, J. L., Oliveira, W. A., Braga, I. F., Farias, M. S., Lizzi, E. A. S., Gonçalves, M. F. C., ... Silva, M. A. I. (2016). The effects of a skillbased intervention for victims of bullying in Brazil. International Journal of Environmental Research and Public Health, 13(10), 1042-1052. doi: 10.3390/ijerph13111042

Silva, P. F., Freller, C. C., Alves, L. S. L., \& Saito, G. K. (2017). Limites da consciência de professores a respeito dos processos de produção e redução do bullying. Psicologia USP, 28(1), 44-56. doi: 10.1590/0103-656420150129.

Smith, P. K., \& Shu, S. (2000). What good schools can do about bullying Findings from a survey in English schools after a decade of research. Childhood, 7(2), 193-212. doi: 10.1177/0907568200007002005

Ttofi, M. M., \& Farrington, D. P. (2009). What works in preventing bullying: effective elements of anti-bullying programmes. Journal of Aggression, Conflict and Peace Research, 1(1), 13-24. doi: 10.1108/17596599200900003

Waasdorp, T. E., Bradshaw, C. P., \& Duong, J. (2011). The link between parents' perceptions of the school and their responses to school bullying: variation by child characteristics and the forms of victimization. Journal of Educational Psychology, 103(2), 324-335. doi: 10.1037/a0022748 
Whitney, I., \& Smith, P. K. (1993). A survey of the nature and extent of bully/victim problems in junior/middle and secondary schools. Educational Research, 35(1), 3-25. doi: 10.1080/0013188930350101

Williford, A., Boulton, A. J., \& Jenson, J. M. (2014). Transitions between subclasses of bullying and victimization when entering middle school. Aggressive Behavior, 40(1), 24-41. doi: 10.1002/ab.21503
Zaine, I., Reis, M. J. D., \& Pandovani, R. C. (2010). Comportamentos de bullying e conflito com a lei. Estudos de Psicologia, 27(3), 375-382. doi: 10.1590/S0103-166X2010000300009

Zequinão, M. A.; Cardoso, A. A.; Silva, J. L.; Medeiros, P.; Silva, M. A. I.; Pereira, B.; Cardoso, F. L. (2017). Academic performance and bullying in socially vulnerable students. Journal of Human Growth and Development, 27(1), 19-27. doi: 10.7322/jhgd.127645

Jorge Luiz da Silva, Doutor em Enfermagem em Saúde Pública pela Escola de Enfermagem de Ribeirão Preto da Universidade de São Paulo (EERP-USP). Endereço para correspondência: Escola de Enfermagem de Ribeirão Preto (EERP/USP) Sala 72 Avenida Bandeirantes, 3900, CEP - 14040-902 Ribeirão Preto - SP. E-mail: jorgelsilva@usp.br

Wanderlei Abadio de Oliveira, Doutor em Enfermagem em Saúde Pública pela Escola de Enfermagem de Ribeirão Preto da Universidade de São Paulo (EERP-USP). Professor Contratado

III (Doutor) da Escola de Enfermagem de Ribeirão Preto da Universidade de São Paulo (EERP-USP). E-mail: wanderleio@usp.br

Julliane Messias Cordeiro Sampaio, Doutora em Enfermagem em Saúde Pública pela Escola de Enfermagem de Ribeirão Preto da Universidade de São Paulo (EERP-USP). Professora Assistente do Centro Universitário do Distrito Federal (UDF). E-mail: enfajulliane@yahoo.com.br

Fellipe Soares Salgado, Mestre em Psicologia pela Universidade Federal de Juiz de Fora (UFJF). Doutorando em Psicologia na Faculdade de Filosofia, Ciências e Letras de Ribeirão Preto da Universidade de São Paulo (FFCLRP-USP).

E-mail: fellipe.salgado@yahoo.com

Beatriz Oliveira Pereira, Doutora em Estudos da Criança pela Universidade do Minho (UM).

Professora Catedrática do Centro de Investigação em Estudos da Criança da Universidade do Minho (CIEC-UM). E-mail: beatriz@ie.uminho.pt

Marta Angélica lossi Silva, Doutora em Enfermagem em Saúde Pública pela Escola de Enfermagem de Ribeirão Preto da Universidade de São Paulo (EERP-USP). Professora Associada da Escola de Enfermagem de Ribeirão Preto da Universidade de São Paulo (EERP-USP).E-mail: maiossi@eerp.usp.br 